\title{
Arthralgia in Children - Case Series
}

Janani Sankar* and R. Venkateswari

Consultant Pediatricians, Kanchi Kamakoti Childs Trust Hospital, The Childs Trust Medical Research Foundation, Chennai, India

"Corresponding author: Janani Sankar, Consultant Pediatricians, Kanchi Kamakoti Childs Trust Hospital, The Childs Trust Medical Research Foundation, Chennai, India, Tel: 0444200 1800; E-mail: janani.sankar@yahoo.com

Rec date: November 13, 2015; Acc date: December 24, 2015; Pub date: December 31, 2015

Copyright: (C) 2015 Sankar J, et al. This is an open-access article distributed under the terms of the Creative Commons Attribution License, which permits unrestricted use, distribution, and reproduction in any medium, provided the original author and source are credited.

\section{Introduction}

Joint pain is a common complaint in children. The cause of joint pain can be as simple as a growing pain or a serious cause like infections or malignancy. Differentiating a benign cause of pain from a malignant cause in children is always difficult and challenging. A good clinical history with physical examination aided by lab investigations can usually pinpoint to the exact diagnosis. In the past 1year, we had 3 children with joint pain who were initially diagnosed and treated as osteomyelitis, but on reevaluation were found to have leukemia.

\section{Case Reports}

$2 \frac{1}{2} \mathrm{yr}$ old male child was evaluated for complaints of pain in the left leg and limping gait of 1 week duration. There was no local swelling or tenderness, but ROM of left hip was restricted due to pain and spasm. There was no significant pallor or lymphadenopathy or organomegaly. Investigations showed normal white cell count (5000 cells/cumm), high ESR $(86 \mathrm{~mm} / \mathrm{hr})$, positive CRP $(26 \mathrm{mg} / \mathrm{L})$. MRI pelvis showed features of osteomyelitis left ischium and child was treated with parenteral antibiotics.

Child had recurrence of limb pain after a month and was reevaluated. Complete blood count showed leucopenia (3400 cells/ cumm) and peripheral smear showed $15 \%$ blasts. Bone marrow smear and flow cytometry was consistent with CALLA positive ALL.

$7 \frac{1}{2} \mathrm{yr}$ old girl child was brought with complaints of left shoulder pain and low back pain interfering with day to day activities for 2 months. There was history of low grade undocumented fever. She was treated as left humerus osteomyelitis elsewhere.

On examination, she was afebrile with no significant pallor or lymphadenopathy or organomegaly. However, she had significant low back pain and resented examination. Complete blood count was normal (TC - 7200 cells/cumm, Hb-10.7 gm/dl, platelet count-2.8 lakhs/cumm). ESR was high $(112 \mathrm{~mm} / \mathrm{hr})$. Bone marrow smear showed plenty of lymphoblasts. Flow cytometry was consistent with CALLA positive ALL.

9 yr old girl child was brought with complaints of low grade fever, pain in the right hip for 3 days. There was history of pain in the left shoulder 2months back, for which she was evaluated and treated as humerus osteomyelitis elsewhere.

On examination, she was afebrile with no significant pallor or lymphadenopathy or organomegaly. However, she had tenderness over the right ischium and resented examination. Complete blood count was normal (TC -6000 cells/cumm, Hb $-9.8 \mathrm{gm} / \mathrm{dl}$, platelet count -3 lakhs/cumm).

This article was originally published in a special issue, entitled: "Arthritis \& Pain", Edited by Rostyslav V Bubnov
CRP was positive $(106.4 \mathrm{mg} / \mathrm{L})$ and ESR was high $(116 \mathrm{~mm} / \mathrm{hr})$. MRI pelvis showed altered signal intensity in the right iliac bone, right ischial tuberosity, right inferior pubic ramus with adjacent soft tissue edema and minimal collection adjacent to right iliac bone, features favouring osteomyelitis (Table 1).

\begin{tabular}{|l|l|l|l|}
\hline & PATIENT 1 & PATIENT 2 & PATIENT 3 \\
\hline TC (cells/cumm) & 5000 & 7200 & 6000 \\
\hline $\mathrm{Hb}(\mathrm{gm} / \mathrm{dl})$ & 10.2 & 10.7 & 9.8 \\
\hline $\begin{array}{l}\text { Platelet (lakhs/ } \\
\text { cumm) }\end{array}$ & 3.2 & 2.8 & 3 \\
\hline ESR (mm/hr) & 86 & 112 & 116 \\
\hline
\end{tabular}

Table 1: Patients details.

\section{Discussion}

In all the above three children, joint pain was the initial presenting symptom. None of them had significant pallor/bleeds/ lymphadenopathy/organomegaly at the time of presentation. All of them had high inflammatory markers with normal white cell count at presentation. None of them had significant joint pain or joint swelling.

The earliest signs and symptoms of osteomyelitis are often subtle and non-specific. Neonates can present with pseudoparalysis. Infants and older children are more likely to have fever, pain and localizing signs such as warmth, edema and erythema. The white blood cell count, CRP, ESR are generally elevated in children with osteomyelitis but are non-specific and not helpful in distinguishing from other inflammatory processes.

The initial presentation of ALL is usually non-specific. Anorexia, malaise, irritability, low grade fever are often present. Sometimes the predominant symptom can be bone or joint pain. Bone pain in leukemia is usually severe and can wake the patient at night. Symptoms of bone marrow failure and organ infiltration will not be obvious at the time of presentation. There may be exquisite tenderness over the bone or objective evidence of joint swelling and effusion. With marrow involvement, deep bone pain may be present but tenderness will not be elicited.

Hence, in any child who presents with joint pain and high inflammatory markers, the possibility of malignancy should always be kept in mind and we should look for subtle clues for diagnosis. 